\title{
Aspectos biológicos de Dichelops melacanthus em três temperaturas, alimentados com grãos imaturos de milho $2 \mathrm{~B} 688 \mathrm{Hx}$ e $2 \mathrm{~B} 688$
}

\author{
Biological aspects of Dichelops melacanthus at three temperature, reared on \\ immature $2 \mathrm{~B} 688 \mathrm{Hx}$ and $2 \mathrm{~B} 688$ corn grains
}

\author{
Orcial Ceolin Bortolotto $^{I^{*}}$ Adriana Yatie Mikami ${ }^{I}$ Adeney de Freitas Bueno ${ }^{\mathrm{I}, \text { II }}$ \\ Gabriela Vieira Silva' Ana Paula de Queiroz ${ }^{\text {III }}$
}

\section{RESUMO}

\begin{abstract}
Este estudo investigou os aspectos biológicos de Dichelops melacanthus (Hemiptera: Pentatomidae) em três temperaturas $\left(19 \pm 1^{\circ} \mathrm{C}, 25 \pm 1^{\circ} \mathrm{Ce} 31 \pm 1^{\circ} \mathrm{C}\right)$, alimentados com grãos imaturos de milho $2 B 688 H x$ (expressa a proteina inseticida CrylF, para o controle de lepidópteros-alvo) e 2B688. Foi observado que a temperatura de $19 \pm 1^{\circ} \mathrm{C}$ prejudicou o desenvolvimento de $\boldsymbol{D}$. melacanthus, pois, nessa condição, foi registrada a maior taxa de mortalidade das ninfas, menor peso de adultos e as fêmeas não ovipositaram. Por outro lado, a duração da fase jovem mortalidade, peso de adultos, fecundidade e viabilidade de ovos não diferiu entre as temperaturas $25 \pm 1^{\circ} \mathrm{C}$ e $31 \pm 1^{\circ} \mathrm{C}$. Também foi demonstrado que os aspectos biológicos dos percevejos alimentados com grãos imaturos de milho $2 B 688 H x$ não diferiram dos que se desenvolveram com a isolinha 2B688. Este estudo comprova que D. melacanthus desenvolve-se melhor em condições de temperaturas mais elevadas (até $31 \pm 1^{\circ} \mathrm{C}$ ), e o fato de se alimentar com grãos imaturos de milho 2 B688Hx não afeta o seu desenvolvimento.
\end{abstract}

Palavras-chave: percevejo barriga-verde, resistência varietal, pragas iniciais, pragas do milho.

\section{ABSTRACT}

This study investigated the development of Dichelops melacanthus (Hemiptera: Pentatomidae) at different temperatures $\left(19 \pm 1^{\circ} \mathrm{C}, 25 \pm 1^{\circ} \mathrm{C}\right.$ and $31 \pm 1^{\circ} \mathrm{C}$ ) reared on $2 \mathrm{~B} 688 \mathrm{Hx}$ (expressing Cryl $\mathrm{F}$ insectice protein to control lepidopterans target) immature corn grains. The temperature of $19 \pm 1^{\circ} \mathrm{C}$ impaired the development of $\boldsymbol{D}$. melacanthus and recorded the highest mortality of nymphs, lower weight and adult females laid no eggs. Moreover, the length of the nymphal biology, adult weight, fecundity and viability of eggs did not differ between temperatures $25 \pm 1^{\circ} \mathrm{C}$ and $31 \pm 1^{\circ} \mathrm{C}$. It was also shown that the biological aspects of green belly stink bugs fed with 2 B688Hx immature grains of corn do not differ from that develop with $2 B 688$ isoline. This study showed that the biological cycle of D. melacanthus is favored at warmer temperature (until $31 \pm 1^{\circ} \mathrm{C}$ ), and the consume of immature corn grain $2 B 688 H x$ does not affect its development.

Key words: green belly stink bug, varietal resistence, initial pests, corn pests.

\section{INTRODUÇÃO}

O percevejo barriga-verde Dichelops melacanthus(Hemiptera:Pentatomidae) tem crescido em importância recentemente, principalmente em razão da capacidade de ocasionar danos na cultura do milho (ROZA-GOMEZ et al., 2011). No Brasil, essa espécie encontra-se distribuída principalmente nas regiões produtoras entre o norte do Paraná e o CentroOeste, provavelmente, em razão das temperaturas mais elevadas. Recentemente, estudos têm indicado um cenário de elevação da temperatura média do globo terrestre (IPCC, 2014), e esse fato pode impactar diretamente sobre a biodinâmica dos insetos. De acordo com CHRISTENSEN (2007), sutis alterações na temperatura já são suficientes para comprometer o desenvolvimento dos organismos mais suscetíveis. Além disso, a temperatura também apresenta influência sobre a distribuição geográfica das pragas (TOUGOU et al., 2009), o que pode justificar a maior ou menor abundância de uma determinada espécie em diferentes regiões produtoras.

\footnotetext{
IPrograma de Pós-graduação em Entomologia, Departamento de Zoologia, Universidade Federal do Paraná (UFPR), 81531-980, Curitiba, PR, Brasil. E-mail: bortolotto.orcial@gmail.com. *Autor para correspondência.

ILaboratório de Controle Biológico, Embrapa Soja, Londrina, PR, Brasil.

IIIPrograma de Pós-graduação em Agricultura Conservacionista, Instituto Agronômico do Paraná (IAPAR), Londrina, PR, Brasil
} 
Adicionalmente, além da temperatura, o sucesso no desenvolvimento de uma espécie está associado com a abundância e qualidade dos alimentos. Atualmente, o sistema produtivo de milho é representado em sua maioria pelo cultivo de linhagens de híbridos resistentes à pragas, que expressam o gene da bactéria inseticida Bacillus thuringiensis (Bt) (JAMES, 2013). No Brasil, a maioria desses materiais resistentes tem sido desenvolvida para o controle da lagarta-do-cartucho Spodoptera frugiperda (Lepidoptera: Noctuidae) (SANTOS et al., 2012). No entanto, estudos têm indicado que essa tecnologia (cultivo $B t$ ) pode afetar também o desenvolvimento de organismos não-alvo (PONS et al. 2005, VIRLA et al., 2010).

Embora os danos ocasionados por $\boldsymbol{D}$. melacanthus em milho ocorram na fase vegetativa do milho, a espécie não é capaz de completar o ciclo biológico alimentando-se apenas com o colmo das plantas (CHOCOROSQUI \& PANIZZI, 2008). Por outro lado, a disponibilidade de grãos, maduros ou imaturos, permite que os insetos atinjam a fase adulta e se reproduzam (CHOCOROSQUI \& PANIZZI, 2008). Desse modo, em uma lavoura de milho $B t$, os indivíduos podem sobreviver alimentando-se dos grãos maduros que permanecem junto aos restos culturais, porém os possíveis impactos da ingestão desse material sobre a espécie D. melacanthus ainda não tem sido estudada. Em razão da escassez dessas informações, este estudo objetivou investigar o impacto de três temperaturas sobre os aspectos biológicos de D. melacanthus, assim como possíveis impactos dos grãos de milho $B t$ 2B688Hx (expressa a proteína inseticida Cry1F) sobre o desenvolvimento da praga não-alvo.

\section{MATERIAL E MÉTODOS}

\section{Criação e multiplicação de D. melacanthus}

As posturas de D. melacanthus para a realização do experimento foram obtidas de uma colônia pertencente ao laboratório de criação de insetos do Instituto Agronômico Paranaense (IAPAR - Londrina, Paraná), na qual está estabelecida por 19 anos. A criação dos insetos ocorreu com a oferta de uma dieta natural, composta por grãos de soja, amendoim, girassol e vagens de feijão. Esses indivíduos desenvolveram-se em condições controladas de temperatura $\left(25 \pm 1^{\circ} \mathrm{C}\right)$, umidade relativa $(60 \pm 10 \%)$ e fotofase $(14 \mathrm{~h})$.

Cultivo do milho e preparo do material utilizado nos bioensaios
Para a realização do estudo, foram utilizadas isolinhas de milho $B t$ (Herculex ${ }^{\circledR} \mathrm{I}-2 \mathrm{~B} 688 \mathrm{Hx}$, evento TC1507) e não Bt (2B688). O milho Bt expressa o gene cry $1 \mathrm{~F}$, que confere ação inseticida de alta dose à $\boldsymbol{S}$. frugiperda e outros lepidópteros que atacam a cultura (SANTOS et al., 2012). Esses híbridos de milho utilizados no estudo são cultivados para produção de silagem, porém também são afetados adversamente por infestação de pragas (OTA et al., 2011).

$\mathrm{O}$ cultivo do milho foi realizado em duas casas de vegetação separadas, para evitar a polinização cruzada entre os materiais $B t$ e não $B t$. A semeadura foi realizada em vasos de $8 \mathrm{~L}$, contendo terra esterilizada. $\mathrm{O}$ manejo nutricional do milho foi realizado com adubação de acordo com as recomendações técnicas para a região (FANCELLI \& NETO, 2007). O manejo fitossanitário da cultura (uso de herbicidas, fungicidas ou inseticidas) não foi realizado, para não influenciar no estudo. A coleta de espigas ocorreu no estádio de grão pastoso (R4), sendo imediatamente descascadas para oferta aos percevejos.

Biologia de D. melacanthus alimentados com milho 2B688Hx e 2B688 em três temperaturas

$\mathrm{O}$ ensaio foi conduzido em delineamento experimental inteiramente casualizado em esquema

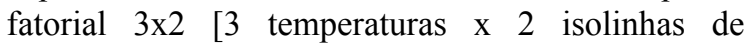
milho]. As temperaturas em que os espécimes foram submetidos foram $19 \pm 1,25 \pm 1$ e $31 \pm 1^{\circ} \mathrm{C}$, em condições controladas com umidade relativa de $60 \pm 20 \%$ e fotofase de $14 \mathrm{~h}$. Para alimentação dos insetos, foram ofertados, ad libitum, grãos imaturos de milho $B t(2 \mathrm{~B} 688 \mathrm{Hx})$ e sua isolinha não $B t$ (2B688) até atingirem a fase adulta.

\section{Avaliação dos aspectos biológicos da fase ninfal de} D. melacanthus

Ninfas de segundo ínstar foram individualizadas em placas de Petri $(6 \mathrm{~cm}$ de diâmetro), com o fundo forrado com papel filtro. A tampa dessas placas foi perfurada ( $1 \mathrm{~cm}$ de diâmetro) para permitir a troca gasosa e reduzir a evaporação dentro da placa. O experimento foi instalado com 14 repetições $(\mathrm{n}=5$ indivíduos/repetição, totalizando 70 ninfas por tratamento).

Dentro de cada placa de Petri, junto ao alimento, também foi disponibilizada água para os insetos, por meio de um algodão embebido em água em um microtubo plástico do tipo Eppendorf ${ }^{\circledR}$. Para a manutenção de umidade dentro das placas, elas foram umedecidas diariamente com auxílio de uma piceta. A troca de alimentos e do papel filtro ocorreu 
em intervalo de até $48 \mathrm{~h}$, sendo trocado sempre que necessário (contaminação do alimento). Diariamente, foi avaliado o ínstar dos insetos e o número de indivíduos mortos, para calcular a duração da fase ninfal (dias) e sobrevivência (\%) em cada tratamento.

Avaliação dos aspectos biológicos da fase adulta de

\section{Melacanthus}

Os adultos foram pesados $24 \mathrm{~h}$ após a emergência, com o auxílio de uma balança analítica com precisão de quatro casas decimais. Posteriormente, realizou-se a separação por sexo e a formação de casais para a avaliação dos parâmetros reprodutivos das fêmeas. Em razão da maior emergência de fêmeas, foi colocada a proporção de duas fêmeas para cada macho em cada caixa tipo Gerbox ${ }^{\circledR}$. Assim como as placas de Petri, essas caixas acrílicas também foram forradas com papel filtro e foram realizadas duas perfurações na tampa (para permitir o fluxo de ar e impedir o excesso de umidade). Após a perfuração, foi colocada uma tela milimétrica sobre cada orifício, para evitar a fuga dos indivíduos.

A manutenção dos casais adultos (troca do alimento e a troca do papel filtro) seguiu a mesma metodologia estabelecida para as ninfas. No total, foram utilizadas oito repetições, sendo que cada repetição foi constituída por uma caixa Gerbox ${ }^{\circledR}$. As avaliações dos parâmetros da fase adulta foram realizadas no intervalo de até 30 dias após a primeira oviposição. Os parâmetros avaliados foram: peso do adulto (mg), fecundidade das fêmeas (número total de ovos) e viabilidade dos ovos (\%). Dentro de cada Gerbox $^{\circledR}$, foi colocado um chumaço de algodão que serviu como substrato para oviposição das fêmeas, facilitando a coleta de ovos. Os ovos foram coletados a cada $48 \mathrm{~h}$ e imediatamente quantificados, para posterior acondicionamento em placas de Petri ( $6 \mathrm{~cm}$ de diâmetro). Após isso, as placas foram colocadas novamente em suas respectivas condições de temperatura, para averiguar a eclosão de ninfas e calcular a viabilidade (\%) dos ovos.

Análise estatística

Todos os dados foram inicialmente submetidos aos testes de normalidade e homogeneidade, para verificar se atendiam aos pressupostos da estatística paramétrica. A partir disso, realizou-se a análise de variância (ANOVA) pelo teste de Tukey. A diferença foi considerada significativa quando $P \leq 0,05$ (SAS Institute, 2001). Todos os dados de porcentagem foram transformados utilizando-se a fórmula arcsen $\left[(\mathrm{x} / 100)^{1 / 2}\right]$.

\section{RESULTADOS}

Neste estudo, foi observado que as temperaturas $25 \pm 1{ }^{\circ} \mathrm{C}$ e $31 \pm 1^{\circ} \mathrm{C}$ favoreceram o desenvolvimento ninfal de D. melacanthus, pois reduziram a duração da fase jovem e proporcionaram as maiores taxas de sobrevivência (Tabela 1). Porém, os indivíduos submetidos à temperatura de $19 \pm 1^{\circ} \mathrm{C}$ foram prejudicados, pois tiveram um prolongamento da duração da fase ninfal e um elevado índice de mortalidade (Tabela 1). Os adultos desenvolvidos nas temperaturas de $25 \pm 1^{\circ} \mathrm{C}$ e $31 \pm 1^{\circ} \mathrm{C}$ apresentaram semelhança de peso (Tabela 2), assim como na fecundidade média (70 ovos fêmea ${ }^{-1}$ ) e viabilidade dos ovos (aproximadamente 79\%). Por outro lado, os adultos oriundos da temperatura de $19 \pm 1{ }^{\circ} \mathrm{C}$ tiveram a biologia prejudicada, pois, além do menor peso, as fêmeas não ovipositaram (Tabela 2).

Quando comparada a influência do alimento sobre a biologia de D. melacanthus, os resultados não indicaram diferença entre os dois tratamentos em nenhuma temperatura avaliada (Tabelas 1 e 2). Adicionalmente, foi observado que a duração da fase ninfal e a sobrevivência também

Tabela 1 - Influência da temperatura sobre os aspectos biológicos da fase ninfal de Dichelops melacanthus alimentados com grãos imaturos de milho $B t 2 \mathrm{~B} 688 \mathrm{Hx}$ e não $\mathrm{Bt}$ 2B688.

\begin{tabular}{lll}
\hline \multirow{2}{*}{ Tratamento } & \multicolumn{2}{c}{------Parâmetros da fase ninfal------ } \\
& Duração (d) & Sobrevivência (d) \\
\hline $19 \pm 1^{\circ} \mathrm{C}$ & $62,83 \pm 1,01 \mathrm{a}$ & $26,43 \pm 1,80 \mathrm{a}$ \\
$25 \pm 1^{\circ} \mathrm{C}$ & $25,40 \pm 0,49 \mathrm{~b}$ & $67,86 \pm 3,76 \mathrm{~b}$ \\
$31 \pm 1^{\circ} \mathrm{C}$ & $18,48 \pm 0,46 \mathrm{~b}$ & $72,86 \pm 3,29 \mathrm{~b}$ \\
Milho Bt (2B688Hx) & $35,53 \pm 3,08^{\mathrm{ns}}$ & $56,67 \pm 3,73 \mathrm{~ns}$ \\
Isolinha não Bt (2B688) & $35,61 \pm 3,11$ & $54,76 \pm 4,42$ \\
CV (\%) & 10,25 & 26,06 \\
GL temp. & 2 & 2 \\
GL isol. & 1 & 1 \\
GL temp. x isol. & 2 & 2 \\
F temp. & 1198,17 & 47,70 \\
F isol & 0,01 & 0,18 \\
F temp. x isol. & 2,73 & 1,18 \\
P-valor temp. & $<0,01$ & $<0,01$ \\
P-valor isol. & 0,92 & 0,67 \\
P-valor temp. x isol. & 0,07 & 0,31 \\
& &
\end{tabular}

${ }^{*}$ Médias \pm EPM seguidas pela mesma letra na coluna não diferem entre si pelo teste de $t(\mathrm{P} \leq 0,05)$. Ns - não significativo. Obs.: devido a não haver diferença na biologia de $D$. melacanthus quando alimentados com o milho 2B688Hx e 2B688, apresentouse apenas a média geral (das três temperaturas).

Ciência Rural, v.46, n.2, fev, 2016. 
Tabela 2 - Influência da temperatura sobre o peso de adultos, número de ovos e viabilidade de ovos de Dichelops melacanthus alimentado com milho Bt 2B688Hx e não Bt 2B688.

\begin{tabular}{llll}
\hline Tratamento & Peso de adultos (mg) & Fecundidade & Viabilidade de ovos (\%) \\
\hline $19 \pm 1^{\circ} \mathrm{C}$ & $34,0 \pm 1,7 \mathrm{~b}^{*}$ & - & - \\
$25 \pm 1^{\circ} \mathrm{C}$ & $41,2 \pm 1,5 \mathrm{a}$ & $70,16 \pm 7,73^{\mathrm{ns}}$ & $79,77 \pm 3,83^{\mathrm{ns}}$ \\
$31 \pm 1^{\circ} \mathrm{C}$ & $38,2 \pm 0,9 \mathrm{a}$ & $68,81 \pm 5,35$ & $79,48 \pm 4,16$ \\
Milho Bt (2B688Hx) & $38,0 \pm 1,4^{\mathrm{ns}}$ & $62,22 \pm 6,48^{\mathrm{ns}}$ & $83,70 \pm 4,62^{\mathrm{ns}}$ \\
Isolinha não Bt (2B688) & $37,6 \pm 2,1$ & $76,75 \pm 6,27$ & 17,84 \\
CV (\%) & 11,48 & 37,80 & 1 \\
GL temp. & 2 & 1 & 1 \\
GL isol. & 1 & 1 & 1 \\
GL temp. x isol. & 2 & 1 & 0,04 \\
F temp. & 10,23 & 0,02 & 1,30 \\
F isol & 0,01 & 2,45 & 0,97 \\
F temp. x isol. & 2,08 & 0,29 & 0,84 \\
P-valor temp. & $<0,01$ & 0,89 & 0,26 \\
P-valor isol. & 0,92 & 0,13 & 0,33 \\
P-valor temp. x isol. & 0,14 & 0,59 & \\
\hline
\end{tabular}

${ }^{*}$ Médias \pm EP seguidas pela mesma letra na coluna, temperatura e cultivar, não diferem entre si pelo teste de Tukey e teste $t$ ( $\left.\mathrm{P}=0,05\right)$. NS não significativo. Obs.: devido a não haver diferença na biologia de D. melacanthus quando alimentados com o milho 2B688Hx e 2B688, apresentou-se apenas a média geral (das três temperaturas).

foram similares (Tabela 1). Essa semelhança dos parâmetros biológicos foi observada também para os insetos adultos, onde o peso de adultos, fecundidade e viabilidade dos ovos não diferiu entre os tratamentos (Tabela 2).

\section{DISCUSSÃO}

Apesar de o fenômeno "aquecimento global" ainda ser muito contestado, estudos já têm indicado que a sua possível ocorrência poderá favorecer ou prejudicar o desenvolvimento e a biodinâmica de muitas pragas agrícolas (KARUPPAIAH \& SUJAYANAD, 2012). Nesse sentido, em uma suposta condição de elevação da temperatura média global, a espécie D. melacanthus pode ser favorecida no agroecossistema, pois nosso estudo demonstrou que a biologia da espécie não é afetada mesmo na condição de temperatura constante de $30^{\circ} \mathrm{C}$.

Por outro lado, este trabalho indica que, em condições de temperaturas mais baixas, essa praga poderá ser prejudicada. Isso foi evidenciado pelo alto índice de mortalidade das ninfas desenvolvidas na condição de $19^{\circ} \mathrm{C}$. No estudo de CHOCOROSQUI \& PANIZZI (2002), os autores verificaram que as temperaturas de $15^{\circ} \mathrm{C}$ e $20^{\circ} \mathrm{C}$ prejudicaram o desenvolvimento ninfal de D. melacanthus, assemelhando-se ao presente estudo. Nesse mesmo trabalho, os autores evidenciaram que a condição ótima para a biologia das ninfas foi a $25^{\circ} \mathrm{C}$. Apesar disso, os autores não avaliaram a biologia dos adultos, e também não investigaram o impacto de temperaturas acima de $25^{\circ} \mathrm{C}$ sobre o desenvolvimento da praga. Nesse sentido, o presente estudo comprovou que, na condição de $31^{\circ} \mathrm{C}$, o ciclo biológico da praga não foi afetado, justificando porque esta espécie distribui-se em regiões produtoras onde ocorrem as temperaturas mais quentes. De forma similar ao registrado para D. melacanthus, o percevejo-marrom Euschistus heros (Hemiptera: Pentatomidae) também não é afetado mesmo em temperatura constante de $30^{\circ} \mathrm{C}$ (CIVIDANES \& PARRA, 1994a). Entretanto, o percevejo-verde Nezara viridula (Hemiptera: Pentatomidae) apresenta melhor adaptação às temperaturas mais amenas $\left(25^{\circ} \mathrm{C}\right)$, sendo que as fêmeas não ovipositam quando submetidas à temperatura de $30^{\circ} \mathrm{C}$ (CIVIDANES \& PARRA, 1994b).

Desse modo, em uma simulação de projeção futura de elevação da temperatura média global, é provável que espécies menos suscetíveis ao calor, como é o caso de D. melacanthus, tenham uma vantagem adaptativa em relação às espécies menos tolerantes. Adicionalmente, é importante enfatizar que essa condição poderá alterar a distribuição geográfica da praga, com migração para regiões onde 
atualmente não ocorrem. Isso já foi evidenciado no Japão, onde a espécie Nezara antenatta (Hemiptera: Pentatomidae) está se deslocando das regiões mais quentes para locais com temperaturas mais amenas (TOUGOU et al., 2009).

Neste estudo, foi demonstrado que a proteína Cry1F expressa nos grãos de milho do híbrido 2B688Hx não afeta o desenvolvimento e os parâmetros reprodutivos de D. melacanthus. A biologia de D. melacanthus em grãos imaturos de milho já foi estudada por PANIZZI et al. (2007), em que os autores registraram que as ninfas demoraram aproximadamente 22 dias para atingir a fase adulta, com $27 \%$ de mortalidade. Esses resultados assemelham-se aos obtidos no presente estudo, para o híbrido de milho Bt 2B688Hx e sua isolinha não Bt. A semelhança dos parâmetros da fase adulta comprova que a ingestão do evento $B t$ não afetou a biologia de D. melacanthus. Isso é reforçado pelo fato de ambos os tratamentos terem apresentado viabilidade e fecundidade praticamente duas vezes superiores ao obtido por PANIZZI et al. (2007).

Embora o milho Bt seja desenvolvido principalmente para o controle de lepidópteros, algumas pesquisas têm demonstrado que insetos sugadores também podem ser afetados. Por exemplo, KIM et al. (2012) evidenciaram que o pulgão-docolmo Rhopalosiphum padi (Hemiptera: Aphididae) apresentou maior fecundidade quando desenvolvidos em milho $B t$ com expressão da proteína inseticida Cry1F. Dentre as possíveis razões para explicar essa relação, destaca-se um possível desequilíbrio nutricional no tecido da planta, que pode alterar a concentração de aminoácidos (FARIA et al., 2007). Uma outra evidência similar foi reportada para a cigarrinha Dalbulus maidis (Hemiptera: Cicadellidae), onde se verificou maior abundância dessa praga em lavouras de milho Bt (VIRLA et al., 2010). Entretanto, no presente estudo, a expressão da proteína Cry1F pelo híbrido $2 \mathrm{~B} 688 \mathrm{Hx}$ não alterou o desenvolvimento de D. melacanthus, sugerindo-se que a composição nutricional dos grãos imaturos do evento $B t$ e sua isolinha não $B t$ 2B688 é semelhante. Essa observação assemelha-se ao verificado para outras pragas nãoalvo, conforme reportado para Apolygus lucorum (Hemiptera: Miridae) em algodão Bt (expressão da proteína Cry1Ac) (LI et al., 2012) e Nilaparvata lugens (Hemiptera: Delphacidae) em genótipos de arroz Bt com expressão das proteínas Cry1c e Cry2A (LU et al., 2014). Esses resultados demonstram que a relação artrópode-planta é bastante peculiar, e generalizações devem ser evitadas em razão do comportamento de cada táxon e o evento estudado.
Os resultados obtidos neste estudo podem sugerir que a biologia da praga não é afetada quando os percevejos se alimentam da seiva do colmo da planta, em razão da menor longevidade quando se alimentam da estrutura vegetativa (CHOCOROSQUI \& PANIZZI, 2008). Em um estudo recente, NETTO (2013) relatou menores injúrias ocasionadas por $D$. melacanthus em genótipos de milho $B t$, porém essa relação ainda não é bem compreendida. Nesse sentido, o presente trabalho demonstra que a espécie D. melacanthus consegue completar o ciclo alimentando-se de grãos de milho 2B688Hx sem ser afetada pelo genótipo modificado. Desse modo, principalmente em casos de sucessão milho-milho, o monitoramento da lavoura deve ser realizado previamente à semeadura, para o estabelecimento ou não de alguma estratégia de controle de acordo com os níveis de ação de D. melacanthus recomendados para a cultura subsequente.

\section{CONCLUSÃO}

A biologia de D. melacanthus é prejudicada na temperatura constante de $19^{\circ} \mathrm{C}$, enquanto, em temperaturas mais elevadas (até $31^{\circ} \mathrm{C}$ ), o ciclo biológico é favorecido. A proteína inseticida Cry1F, expressa no milho Bt 2B688Hx, não afeta o desenvolvimento de D. melacanthus.

\section{AGRADECIMENTOS}

Os autores agradecem às agências, Coordenação de Aperfeiçoamento de Pessoal de Nível Superior (CAPES) e Conselho Nacional de Desenvolvimento Científico e Tecnológico (CNPq) pelo suporte financeiro para o desenvolvimento da pesquisa.

\section{REFERÊNCIAS}

CHOCOROSQUI, V.R.; PANIZZI A.R. Nymph and Adult Biology of Dichelops melacanthus (Dallas) (Heteroptera: Pentatomidae) Feeding on Cultivated and Non-Cultivated Host Plants. Neotropical Entomology, v.37, p.356-360, 2008. Disponível em: <http://www.scielo.br/scielo.php?pid=S1519566X2008000400001\&script=sci arttext $>$. Acesso em: 25 ago. 2014. doi: 10.1590/S1519-566X2008000400001.

CHOCOROSQUI, V.R.; PANIZZI, A.R. Influência da temperatura na biologia de ninfas de Dichelops melacanthus (Dallas, 1851) (Heteroptera: Pentatomidae). Semina, v.23, p.217-220, 2002. Disponível em: <http://www.uel.br/revistas/ uel/index.php/semagrarias/article/view/2099>. Acesso em: 12 set. 2014. doi: 10.5433/1679-0359.2002v23n2p217.

CHRISTENSEN, J.H. Regional climate projections. In: [SOLOMON, S. et al. (Eds.)]. Climate Change 2007: The Physical Science Basis. Contribution of Working Group I to the

Ciência Rural, v.46, n.2, fev, 2016. 
Fourth Assessment Report of the Intergovernmental Panel on Climate Change. Cambridge, United Kingdom and New York, NY, USA: Cambridge University, 2007. p.848-940.

CIVIDANES, F.J.; PARRA, J.R.P. Biologia em diferentes temperaturas e exigências térmicas de percevejos pragas da soja: II. Euschistus heros (Fabr.) (Heteroptera: Pentatomidae). Pesquisa Agropecuária Brasileira, v.29, p.1841-1846, 1994a. Disponível em: <http://seer.sct.embrapa.br/index.php/pab/article/view/4241>. Acesso em: 12 out. 2014.

CIVIDANES, F.J.; PARRA, J.R.P. Biologia em diferentes temperaturas e exigências térmicas de percevejos pragas da soja I. Nezara viridula (L.) (Heteroptera:Pentatomidae). Anais da Sociedade Entomológica do Brasil, v.23, p.243-250, 1994b.

FANCELLI, A.L.; DOURADO-NETO, D. Produção de milho. Guaíba: Agropecuária, 2007. 360p.

FARIA, C.A. et al. High susceptibility of $B t$ maize to aphids enhances the performance of parasitoids of lepidopteran pests. PLoS One, v.2, p.1-11, 2007. Disponível em: $<$ http://www.plosone. org/article/info\%3Adoi\%2F10.1371\%2Fjournal.pone.0000600>. Acesso em: 28 nov. 2014. doi: 10.1371/journal.pone.0000600.

IPCC (INTERGOVERNMENTAL ON PANEL OF CLIMATE CHANGE). Climate change 2014. Synthesis report. Online. Disponível em: <http://www.ipcc.ch/report/ar5/syr/>. Acesso em: 15 abr. 2015.

JAMES, C. Global status of commercialized biotech/GM crops Executive summary. Ithaca: ISAAA Briefs, 2013. 13p.

KARUPPAIAH, V.; SUJAYANAD, G.K. Impact of climate change on population dynamics of insect pests. World Journal of Agricultural Sciences, v.8, p.240-246, 2012. Disponível em: $<$ http://www.researchgate.net/publication/259240426 Impact of_climate_change_on_population_dynamics_of_insect_pests/ links/0deec52a945089ba66000000.pdf. >. Acesso em: 12 out. 2014

KIM, Y.H. et al. Assessment of potential impacts due to unintentionally released $B t$ maize plants on non-target aphid Rhopalosiphum padi (Hemiptera: Aphididae). Journal of Asia-Pacific Entomology, v.15, p.443-446, 2012. Disponível em: <http://www.sciencedirect.com/science/article/pii/ S1226861512000167>. Acesso em: 05 nov. 2014. doi: 10.1016/j. aspen.2012.01.005.

LI, G. et al. Impacts of transgenic Bt cotton on a non-target pest, Apolygus lucorum (Meyer-Dür) (Hemiptera: Miridae), in northern China. Crop Protection, v. 30, n.12, 1573-1578, 2012. Disponível em: <http://www. sciencedirect.com/science/article/pii/S0261219411002717>. Acesso em: 13 abr. 2015. doi: 10.1016/j.cropro.2011.08.015.

LU, ZENG-BIN. et al. Transgenic cry1C or cry $2 \mathrm{~A}$ rice has no adverse impacts on the life-table parameters and population dynamics of the brown planthopper, Nilaparvata lugens (Hemiptera: Delphacidae). Pest Management Science, 2014. Disponível em: <http://onlinelibrary.wiley.com/doi/10.1002/ ps.3866/epdf $>$. Acesso em: 13 abr. 2015.

NETTO, J.C. Infestação e danos de Dichelops melacanthus (Dallas, 1851) (Heteroptera: Pentatomidae) em híbridos transgênicos e convencionais de milho, submetidos ao controle químico. Jaboticabal: UNESP, 2013. 56p.

PANIZZI, A.R. et al. Nymph developmental time and survivorship, adult longevity, reproduction and body weight of Dichelops melacanthus (Dallas) feeding on natural and artificial diets. Revista Brasileira de Entomologia, v.51, p.484-488, 2007. Disponível em: <http://www.scielo.br/scielo. php? script $=$ sci_arttext $\&$ pid $=$ S0085-56262007000400013 $>$. Acesso em: 21 nov. 2014

PONS, X. et al. Abundance of non-target pests in transgenic Btmaize: a farm scale study. European Journal of Entomology, v.102, p.73-79, 2005. Disponível em: <http://www.eje.cz/ artkey/eje-200501-0010 abundance of non-target pests in transgenic_bt-maize_a_farm_scale_study.php $>$. Acesso em: $1 \overline{4}$ set. 2014. doi: $10.1 \overline{4} 4 \overline{11}$ /eje. 2005.010 .

ROZA-GOMES, M.F. et al. Injúrias de quatro espécies de percevejos pentatomídeos em plântulas de milho. Ciência Rural, v.41, p.1115-1119, 2011. Disponível em: $<$ http://www. scielo.br/pdf/cr/2011 nahead/a2811 cr3560.pdf>. Acesso em: 12 out. 2014

SANTOS, A.C. et al. Geração Bt. Pelotas: Cultivar Grandes Culturas, 2012. 161p. (Caderno Técnico Cultura do Milho).

OTA, C.E. et al. Desempenho de cultivares de milho em relação à lagarta-do-cartucho. Bragantia, v.70, n.4, p.850-859, 2011. Disponível em: <http://www.scielo.br/pdf/brag/v70n4/18.pdf > Acesso em: 14 maio, 2015

SAS, INSTITUTE. USER'S GUIDE: Statistics. 6.ed. Cary, 2001. 413p.

TOUGOU, D. et al. Some like it hot! Rapid climate change promotes changes in distribution ranges of Nezara viridula and Nezara antennata in Japan. Entomologia Experimentalis et Applicata, v.130, p.249-258, 2009. Disponível em: $<$ http://onlinelibrary.wiley.com/doi/10.1111/j.15707458.2008.00818.x/pdf>. Acesso em: 22 out. 2014. doi: 10.1111/j.1570-7458.2008.00818.x/abstract.

VIRLA, E.G et al. A preliminary study on the effects of a transgenic corn event on the non-target pest Dalbulus maidis (Hemiptera: Cicadellidae). Crop Protection, v.29, p.635-638, 2010. Disponível em: <http://www.sciencedirect.com/science/ article/pii/S0261219409003305>. Acesso em: 29 out. 2014. doi: $10.1016 /$ j.cropro.2009.12.019. 